\title{
Evaluation Research on Intensive Land Use of Modern Agricultural Park
}

\author{
Chun YANG \\ College of Management, Sichuan Agricultural University \\ Chengdu, 611130, China \\ Wen-kuan CHEN* \\ College of Management, Sichuan Agricultural \\ University \\ Chengdu, 611130, China \\ e-mail:wkc9889@163.com
}

\author{
Lu LI \\ College of Management, Sichuan Agricultural University \\ Chengdu, 611130, China
}

\begin{abstract}
With nearly thirty-year rapid development, contradiction of the demand of sustainable and sound development of agricultural park and limited land supply becomes especially obvious. The article takes the modern agricultural park in Pengxi County, Sichuan Province as an example. Establish the evaluation index system for intensive land use of the park. Land use intensity of Pengxi modern agricultural park from 2011 to 2015 is separately calculated to be $0.3921,0.5152,0.5331,0.5627,0.6320$ by virtue of $\mathrm{BP}$-neural network model. The results showed that, since the establishment of Pengxi modern agricultural park, output effect and use ratio of land in the area has reached a level of preliminarily intensive level, and the increasing state is relative stable, however, it still remains to be improved.
\end{abstract}

Keywords- Agricultural park; intensive land use; BP neutral network; evaluation; Pengxi County

\section{INTRODUCTION}

As a new-type agricultural economical development mode, under the background of tenser environment and resource restriction, agricultural science and technology park plays an important boosting role in promoting transformation and upgrading of traditional agriculture, transformation of agricultural high-tech, moderate scale management and development of multiple forms of agriculture and the implementation of city and countryside integration strategy. The development of agricultural science and technology park has turned the land resources from extensive farming to sustainable and intensive development laying equal stress on "quantity, quantity and benefit".

Usually, in the operation and management of foreign agricultural park, it mainly depends on high-tech to display advanced production method and life style to students and tourists, with three modes Demonstration Farm, Vacation Farm, Educational Farm (Effrey, 2009; BARNEY JB,et al, 2001). Domestic scholars think that agricultural park is a kind of integrated agricultural demonstration base promoting and spreading new products, new technologies and new processes (Chen Shixiong, 2002; Liu Xu, 2012; Zhao Long, 2014). Connotation and boundary of intensive land use is continuously enlarged. Wu Zhigang, Yuan Zhenjie (2015), XieZhengfeng separately enriched the concept of land use from the view point of tourism development and view point of different main functional areas. Scholars, such as Zhou Zuojiang (2014), introduced ecological quality, degree of sustainable development, social benefits index for evaluation of intensive land use. Du Fangfang (2014) established harmonious development evaluation index system of industrial structure and intensive land use by taking advantage of theoretical analysis method and frequency analysis method.

\section{PROFILE OF THE RESEARCH AREA AND DATA SOURCE}

\section{A. Profile of the Research Area}

Pengxi modern agricultural park is located at "golden section ratio" of Chengdu-Chongqing economic corridor, and it is an important pivot for the development of ChengduChongqing dualnuclei cities. The park exactly lies at the development belt of "Penghong line edible mushrooms vegetable industrial belt and national-level modern agricultural demonstration zone" of the "linkage of industrialization, urbanization and functionalization" development strategy and idea, which occupies an important position in the regional economic blocks. The park covers an area of 100 square kilometers, covering 4 towns, namely, Tianfu, Hongjiang, Changle and Mingyue and 43 administrative villages, with the total population of 71,000 , agricultural acreage 100,000 hectares. Up to 2015, the park has built key core area of 40 square kilometers, involving three towns, namely, Tianfu, Hongjiang and Changle and 13 villages, 8,000 households and the population of 28,000 . It is named to be a national modern agricultural demonstration zone by Ministry of Agriculture. Combined with the selfpositioning and development advantages, the park is accelerating to promote the construction of national modern agricultural demonstration zone in the " $1+3$ " development mode integrating "green agriculture + tourism + new countryside". 


\section{B. Data Source}

Taking the complexity for obtaining data index and the convenience of classified statistics and management into consideration, divide the data material types into four aspects: first, structure, degree and intensity of land use; second, land input and output situation; third, overall benefit of economy, society and ecology; forth, management level of the park. Original data involving the first and second aspects mainly comes from Overall Planning for Land Use, Statistical Yearbook of Pengxi (2010-2014), Compilation of Data of the 3rd National Economic Census of Pengxi County, Planning and Design of Tianfu and Hongjiang Modern Agricultural Demonstration Zone of Pengxi County Suining City (20122020) and Annual Working Plan and Summary; Original data involving the third and fourth aspects mainly comes from data provided by Land and Resources Bureau, Agricultural Bureau, Management Committee of the park and villages and towns, assisted with field visiting and investigational study, to get the original data.

\section{ANALYSIS ON CURRENT STATUS OF LAND USE OF PENGXI MODERN AGRICULTURAL PARK}

TABLE I. DYNAMIC CHANGES OF LAND USE IN PENGXI AGRICULTURAL PARK FROM 2011 TO 2015

\begin{tabular}{|c|c|c|c|c|c|}
\hline \multicolumn{2}{|l|}{ Year } & 2011 & 2015 & $\begin{array}{l}\text { Amount } \\
\text { of } \\
\text { increase } \\
\text { and } \\
\text { decrease }\end{array}$ & $\begin{array}{l}\text { Proport } \\
\text { ion of } \\
\text { increas } \\
\text { e and } \\
\text { decreas } \\
\text { e }\end{array}$ \\
\hline \multicolumn{2}{|c|}{$\begin{array}{l}\text { Total land area } \\
\text { (unit: } \mathrm{mu} \text { ) }\end{array}$} & 49913.60 & 49913.60 & 0.00 & $0 \%$ \\
\hline \multirow{6}{*}{$\begin{array}{l}\text { Farm } \\
\text { ing } \\
\text { land }\end{array}$} & Total & 38583.20 & 38691.94 & 108.74 & $0.28 \%$ \\
\hline & $\begin{array}{l}\text { Cultivated } \\
\text { land }\end{array}$ & 31537.00 & 30721.00 & -816.00 & $-2.59 \%$ \\
\hline & Forest land & 5477.90 & 5514.14 & 36.24 & $0.66 \%$ \\
\hline & Grassland & 279.90 & 280.80 & 0.90 & $0.32 \%$ \\
\hline & Garden plot & 769.90 & 756.00 & -13.90 & $-1.81 \%$ \\
\hline & $\begin{array}{l}\text { Facilities } \\
\text { farming } \\
\text { land }\end{array}$ & 518.50 & 1420.00 & 901.50 & $\begin{array}{l}173.87 \\
\%\end{array}$ \\
\hline \multirow{4}{*}{$\begin{array}{l}\text { Cons } \\
\text { tructi } \\
\text { on } \\
\text { land }\end{array}$} & Total & 7174.00 & 8672.62 & 1498.62 & $\begin{array}{l}20.89 \\
\%\end{array}$ \\
\hline & $\begin{array}{l}\text { Residential } \\
\text { area and } \\
\text { land for } \\
\text { mining and } \\
\text { industry }\end{array}$ & 5778.00 & 6602.62 & 824.62 & $\begin{array}{l}14.27 \\
\%\end{array}$ \\
\hline & $\begin{array}{l}\text { Communic } \\
\text { ation and } \\
\text { transportati } \\
\text { on }\end{array}$ & 264.00 & 387.00 & 123.00 & $\begin{array}{l}46.59 \\
\%\end{array}$ \\
\hline & $\begin{array}{l}\text { Water } \\
\text { conservanc } \\
\text { y facilities }\end{array}$ & 1132.00 & 1683.00 & 551.00 & $\begin{array}{l}48.67 \\
\%\end{array}$ \\
\hline $\begin{array}{l}\text { Unus } \\
\text { ed } \\
\text { land }\end{array}$ & $\begin{array}{l}\text { Unused } \\
\text { land }\end{array}$ & 4156.40 & 2549.30 & -1607.10 & $\begin{array}{l}- \\
38.67 \\
\%\end{array}$ \\
\hline
\end{tabular}

Total land area of the core area of Pengxi agricultural park is $49913.60 \mathrm{mu}$, where, farming land is $38692.00 \mathrm{mu}$ (including cultivated land $30721.00 \mathrm{mu}$, it is required that cultivated land quantity shall not be less than $30039.15 \mathrm{mu}$, basic farmland protection area shall not be less than $26411.10 \mathrm{mu}$ ), accounting for $77.40 \%$, construction land is $8672.60 \mathrm{mu}$ (including transit and water conservancy facilities), accounting for $17.38 \%$, unused land is 2549.30 $\mathrm{mu}$ (including fiver and mudflat), accounting for $5.11 \%$.

From 2011 to 2015, land in Pengxi agricultural park is mainly used for agriculture. The park is located at a hilly area, centralizing in developing planting industry, therefore, it is caused by transferring from cultivated land to facility farming land and land use for greening. The area of construction land in the park increases faster, mainly presented as increase of residential area and land area for mining and industry of the region in recent years, reorganization and expansion of roads and other traffic facilities as well as the increase of water conservancy facilities, such as water channels and ditches. The area of the unused land of the park declines obviously, which presented as the sharp increase of the degree of development and utilization of unused land in recent years. Dynamic changes of land use of Pengxi agricultural park from 2011 to 2015 is shown in Table 1.

\section{EVALUATION ON LAND USE INTENSITY OF PENGXI MODERN AGRICULTURAL PARK: METHOD AND DEMONSTRATION}

\section{A. Establishment of Evaluation Index System}

Based on sustainable development theory and the connotation of intensive land use of agricultural park, strictly screen and fill the indexes from the viewing angle of inputoutput-sustainable development. The index system includes the first, second and third grade indexes, where, the first grade index includes land use status, land use benefit and management performance; 7 second grade indexes are included: land use structure, land use degree, investment strength, output effect, sustainability of ecology, socioeconomic status and management performance; 23 third grade indexes are included (Table 2).

Evaluation grade standard is a scientific expression of evaluation results. For the convenience of calculation, the research multiplies intensity of land use by 100 , according to the evaluation score, divides land user levels into four grades, namely, minuent, moderate, intensive and excessive (Table 3).

Where, Y stands for the value of evaluation result multiplied by 100 . The evaluation criteria are transformed on the basis of "sustainable development evaluation criteria of land use".

\section{B. Introduction of Evaluation Methods}

BP neural network is a representative neural network learning algorithm with more application of artificial neural network (ANN) models. Compared with other mathematical methods, the model has strong capacity to deal with nonlinear relationship. It is not a real cranial nerve network. It mainly identifies and processes information through simulating the neural networks of creatures. Main features of the network are that signals transmit forward, error propagating backward. In the process of forward 
transmission, signals are input from input nodes, to the output layer after layer-by-layer processed by the hidden layer. Neuron state of every layer only affects the output of the neurons of the next layer. In case the output layer does not obtained the expected output, it will carry out counterpropagation, adjust network weights and threshold value according to the forecast error, thus, make the predicted output of BP neural network continuously approaching to the expected output.

TABLE II. MODERN AGRICULTURAL PARK LAND INTENSIVE UTILIZATION EVALUATION INDEX

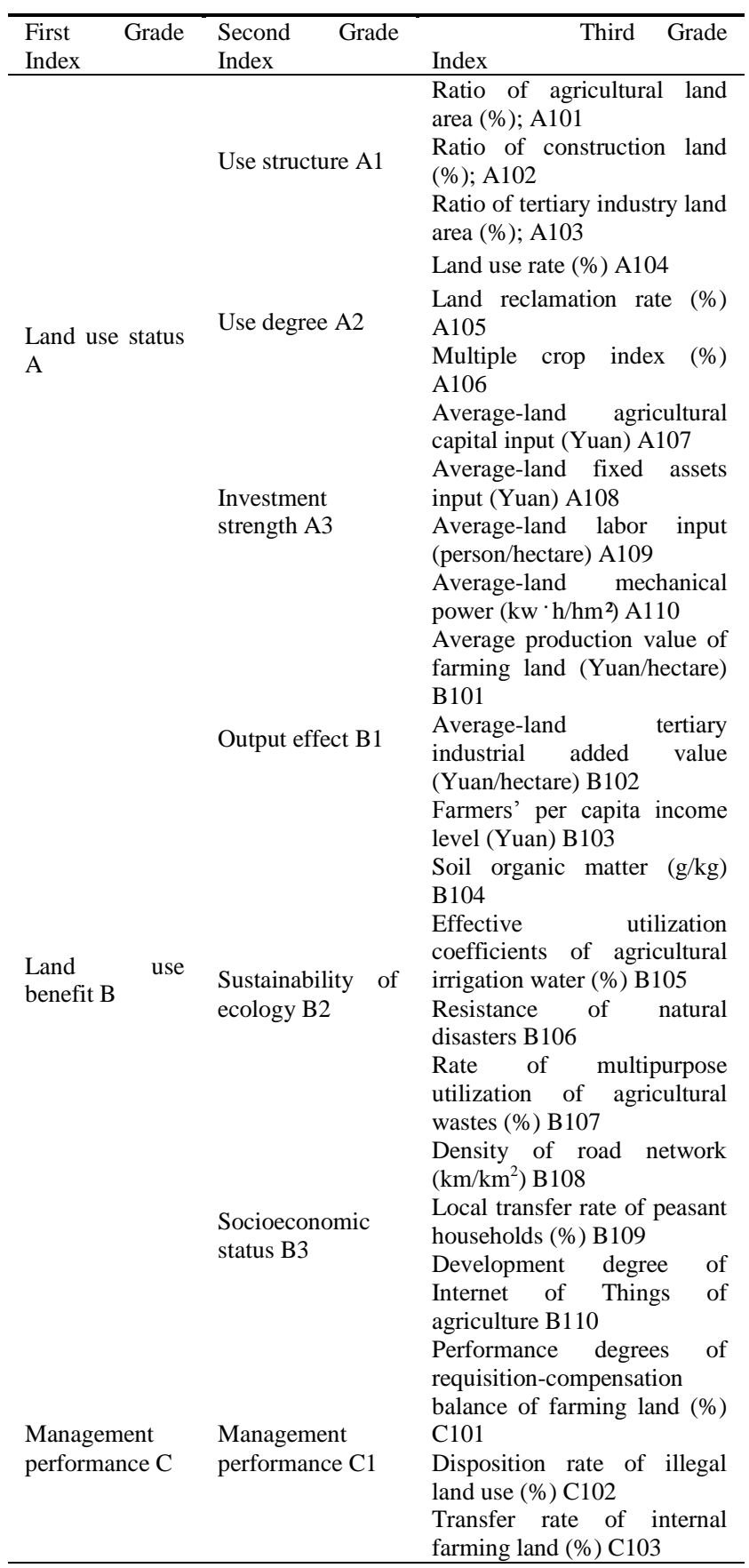

TABLE III. LAND INTENSIVE UTILIZATION EVALUATION RESULTS RATING STANDARD

\begin{tabular}{lllll}
\hline Grade & Minuent & Moderate & Intensive & Excessive \\
\hline Evaluation value $\mathrm{Y}$ & $<40$ & $40-60$ & $60-80$ & $>80$ \\
\hline
\end{tabular}

In the article, standardized ANN training index is the input value of neural network, $\theta_{i}$ is the bounded variable of training function, and $f$ is variable transfer function. After several training, the function iteratively restrains, outputs various post-training index training values, and processes the result value with mean square error, and figures out the final index intensity. Transfer function chosen in the text is:

$$
f(i)=\frac{1}{1+\exp (i)}
$$

\section{Evaluation on Intensive Land Use of Pengxi Modern Agricultural Park}

1) Evaluation Index Data Sorting of Intensive Land Use of the Research Area

We get three first-grade indexes, namely, land use status, land use benefit and management performance, 8 secondgrade indexes evoluted under the index and 23 third-grade indexes through gathering and sorting data of Pengxi modern agricultural park; the research carries out interpolation on the training data of the sample through linear interpolation method, thus, gets the basic training data. Processed data will be translated into standard evaluation value of dimensionless parameters, which conforms to the basic data requirements of neural network model. Comprehensive assessment analysis can be carried out.

\section{2) MATLAB Solution of BP Neural Network Model}

According to the research objects, the article mainly uses BP neural network, and adopts a self-adapting gradient descending training and traingdx function with additional momentum. Therefore, it can offer adequate training on the problem of limited sample capacity, and avoid the problems of slow rate of convergence and low training precision.

Kolmogorov theorem can be used to calculate and determine the number of hidden neurons. In the network, the hidden layer is divided into two layers. The number of hidden neurons can be determined according to the following reference formulate:

$$
\begin{gathered}
\sum_{i=0}^{n} C_{n i}^{i}>k \\
n_{1}=\sqrt{n+m}+a \\
n_{1}=\log _{2} n
\end{gathered}
$$

Where, $\mathrm{k}$ refers to the number of samples, ${ }^{n_{1}}$ refers to the number of hidden units, $\mathrm{n}$ refers to the number of input 
units, $m$ refers to the number of output units, and a shall be a constant in $[1,10]$.

Through repeated training and result contrast, finally, 6 neurons in hidden layer are selected. At the moment, convergence is at the best condition. Neural network structure of the two layers is $23 \times 6 \times 6 \times 1$. According to the output result of neural network model, data result of land use intensity of Pengxi modern agricultural park is sorted out and shown in Table 4, Figure 1 and 2.

TABLE IV. PENG XI AGRICUltural GARDEN ZONE LAND USE INTENSITY OF THE EVALUATION RESULTS IN 2011-2015

\begin{tabular}{llllll}
\hline $\begin{array}{l}\text { Pengxi } \\
\text { Agricultural Park }\end{array}$ & 2011 & 2012 & 2013 & 2014 & 2015 \\
\hline Land Intensity & 0.3921 & 0.5152 & 0.5331 & 0.5627 & 0.6320
\end{tabular}

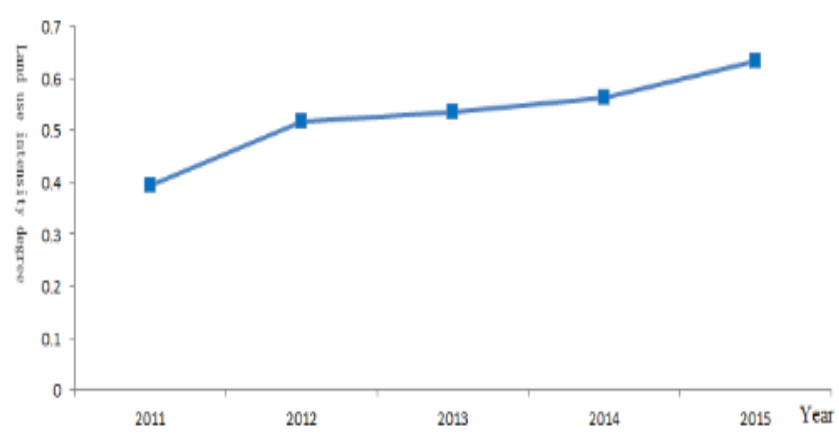

Figure 1. Trend of land use intensity in Pengxi agricultural park from 2011 to 2015

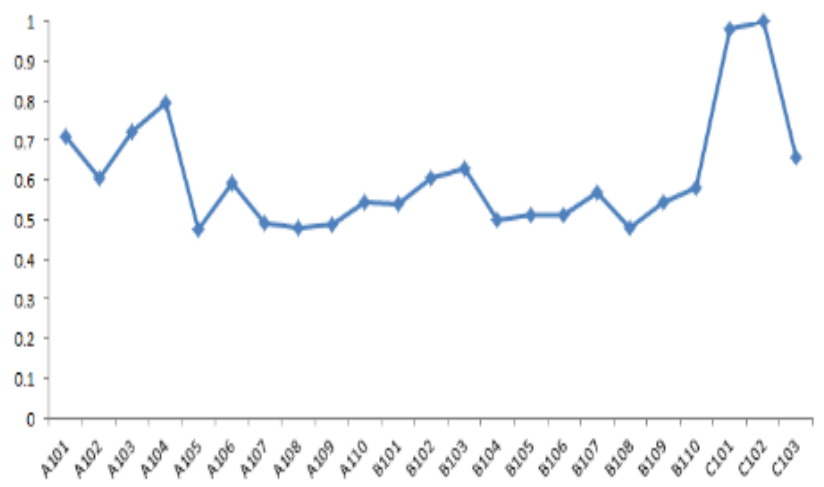

Figure 2. Modern agriculture park land use intensive degree is the standard amount of every index

\section{Result Analysis}

On the whole, intensive use of the land in Pengxi modern agricultural park has reached a preliminarily intensive level. In 2015 , the intensity reached 0.6320 , which illustrates that the agricultural park has made a preliminary progress in land use, land output benefits and operation management. According to the training result, we can easily figure out that it embodied a distinct advantage in land use and management benefits, but reflects an obvious promotional space in land output benefits and effective land supply.
From the intensity variation trend chart, we can see, from 2011 to 2015, intensity of the agricultural park increases from 0.3921 to 0.6320 . The reason is, in 2011, the region did not implement concentrated construction of agricultural parks, therefore, land in this region did not realize intensive farming, and it even failed to reach the effect of effective use. From 2012, the region started the construction of modern agricultural parks. Up to 2015, it has reached a higher intensity. It indirectly reflects the construction of modern agricultural parks can realize effective use of land in the region, obviously raise benefit output and use ratio, moreover, the increasing state is relatively steady.

According to contrastive analysis of standard quantity of intensity of various indexes, get the estimated value of each component against the overall intensity of the park. In land use structure, ratio of agricultural land area is 0.774 , lower than the standard value, while other indexes are above the mean value. The agricultural park performs well in this aspect; land demand quantity increases year by year, therefore, the problem of insufficient effective supply will be revealed year by year, and the park remains to be improved in land use ratio; in the aspect of land investment strength, the overall index output is stable. In the future, the increasing state shall be maintained; in the aspect of overall efficiency of land use, ecological sustainable development has a big gap with the target value. In the future construction and development, pay more attention to further intensifying ecological protection awareness; on the whole, the management level of the park is at a stable development state, however, the potential of internal farming land transfer still exists. Combined with the indexes, the agricultural park is under a good development trend. It achieved its aim of intensive land use. However, it still has development potential.

\section{CONCLUSION}

From 2011 to 2015, intensive land use of Pengxi agricultural park was improved very fast, from low use (below 0.4 ) to preliminary intensive level (above 0.6). The rising tendency is obvious, which illustrates that the construction of agricultural park can improve the level of intensive land use. Keep this tendency, strengthen the excavation of the potential for land exploitation, and reach a higher level of intensive land use.

Compared with the standard quantity of all indexes, land use ratio of tertiary industry, mechanical power input, average-land tertiary industry added value, development degree of agricultural informatization and sustainability of ecology have a large gap with the standard value. Where, the development level of tertiary industry is an important target to realize agricultural transformation and upgrading, mechanical power and informationalized level are important grasps to realize agricultural informatization, and sustainability of ecology is the key to realize ecological, high-efficient, sustainable development. Those are, at present, important factors affecting the intensity level of the park.

At present, reasons for preliminary intensity level are: firstly, backward concept. Intensity not only refers to high economic output, but also refers to replacing traditional 
cultivation method with mechanized, intelligentized, technicalized means. Practice of multiple crop index and labor input in traditional ideas exactly impedes intensive land use. Secondly, indistinctive social effect. Although the construction of the park greatly improves the infrastructure construction level, local transfer rate of peasant households, marketization level of land are at lower level. They did not benefit from the "welfare" that shall be brought by agricultural modernization.

\section{ACKNOWLEDGMENT}

This work is supported byMajor Project of Society Project Planning of Sichuan Province (No. SC14ZD09), the Project of Sichuan educational bureau (No. 12SB079).

\section{REFERENCES}

[1] Luis Lanaspa. Femandopueyo and FemandaSanz[J], The Evolution of Spanish Urban Structure during the Twentieth Century.2003, (40)

[2] Hoch. Income and City Size[J].Urban Studies.2004, (2):311-313

[3] Jiang Heping, Cui Kai. Agricultural Science and Technology Park: Effect, Pattern and Demonstration Keys[J]. Issues in Agricultural Economy, 2009(1): 9-13
[4] Liu Ni, ShuChunge, Li Lintong. Regional Function Division of Land Use in Modern Agriculture Park Sequenced Based on RDA: Taking Nanming Town Jianhe County as an Example[J]. Guizhou Agriculture Science and Technology, 2015, (6): 195-201

[5] Nie Yan, Yu Jing, Hu Jing, etc. Evaluation on Intensive Urban Land Use of Wuhan Based on System's Coordinating Degree[J]. Resource Science, 2009, (11): 1934-1939

[6] Ou Zhaokeng, Tang Nanqi, Zhang Liming. Evaluation on Intensive Land Use of Development Zone Based on BP Artificial Neural Network - Taking Fujian Province as an Example[J]. College Journal of Fujian Agriculture and Forestry University, 2014(4): 424-429

[7] RuanLvyun, Chen Ruofu. Evaluation Research on Intensive Land Use of Development Zone - Taking Wuhan Economic \& Technologica Development Zone as an Example[J]. Natural Resource Economics of China, 2011, (1): 51-53

[8] Wang Qiubing. Land Resource Science[M]. Beijing: China Agriculture Press, 2002

[9] XieTian, Zhang Jing, Zhu Ming. Evaluation Research on Intensive Land Use of Rural-urban Fringe Based on PSR - Taking Qixia District Nanjing as an Example[J]. Resources and Environment of Yangtze Valley, 2013(3): 279-284

[10] Yu Haiying, Wei Ansheng, Chen Zhujun. Analysis and Evaluation of Current Land Use Status of Yangling Demonstration Area[J]. Research on Conservation of Water and Soil, 2015, (5): 158-162 